\title{
PROCESSO DECISÓRIO PARA ESCOLHA DE INVESTIMENTO EM AÇÕES: UMA PROPOSTA UTILIZANDO O MÉTODO DA ANÁLISE HIERÁRQUICA
}

\section{DECISION MAKING FOR STOCK INVESTMENT: A PROPOSAL USING ANALYTIC HIERARCHY PROCESS}

\author{
Eduardo Picanço Cruz ${ }^{1}$; Hugo Leonardo Costa Spindola ${ }^{2}$; Carlos José Guimarães Cova ${ }^{3}$; Carlos \\ Navarro Fontanillas ${ }^{4}$ \\ ${ }^{1}$ Universidade Federal Fluminense - UFF - Rio de Janeiro - Brasil \\ epicanco@vm.uff.br \\ ${ }^{2}$ Pricewaterhouse Coopers Auditores Independentes - PwC \\ hugo.spindola@br.pwc.com \\ ${ }^{3}$ Universidade Federal Fluminense - UFF - Rio de Janeiro - Brasil \\ cjcova@terra.com.br \\ ${ }^{4}$ Universidade Federal Fluminense - UFF / Universidade Federal do Rio de Janeiro - UFRJ - Rio de \\ Janeiro - Brasil \\ navarro@pep.ufrj.br
}

\begin{abstract}
Resumo
A decisão por investir em uma empresa, através do mercado de capitais, frequentemente vem sendo considerada uma aposta de alto risco. Determinar, por exemplo, quais as ações vão compor a carteira de um investidor envolve conhecimento amplo da gestão das empresas para saber o seu potencial de geração de lucro. O objetivo principal do presente trabalho é provocar a discussão acerca da necessidade de se mapear o perfil dos investidores do mercado de ações brasileiro utilizando o Método da Análise Hierárquica, para identificar os motivos que mais pesam na hora de comprar e vender uma ação. A partir dos resultados obtidos em nossa pesquisa de campo, correlacionamos tais resultados com a ciência das finanças comportamentais com vistas a justificar e embasar as conclusões obtidas a partir deste trabalho. Dessa forma, foram aplicados questionários a diferentes pessoas que investem no mercado de ações. Nestes questionários pediase que o entrevistado fizesse uma comparação par-a-par dos fatores de tomada de decisão de acordo com suas preferências, em termos de 4 critérios teste.Esta análise nos permitiu perceber sobre a questão do processo de decisão não confirmando o antigo pressuposto que os investidores agem sempre racionalmente nas decisões do mundo financeiro.
\end{abstract}

Palavras-chave: mercado de ações; método da análise hierárquica; perfis dos investidores brasileiros; finanças comportamentais.

\section{Introdução}

Com o aumento da percepção sobre a importância do conceito de finanças no cotidiano dos cidadãos, fica evidenciada a importância de relacionar o grau de evolução de uma sociedade com o nível de desenvolvimento da sua economia. O processo de globalização vem se tornando um 
fenômeno irreversível, em face da evolução tecnológica. Este fenômeno interliga cada vez mais as sociedades, expandindo os limites das transações financeiras entre os agentes econômicos. Neste processo de evolução, intercâmbio e integração o mercado acionário vem se tornando um componente muito importante para o desenvolvimento econômico de um país e, por conseguinte, vem aumentando sua participação, ou contribuição, para o desenvolvimento da sociedade global.

A partir desta tendência mundial os países em desenvolvimento procuram se inserir neste processo de intercâmbio de informações, abrindo suas economias para o fluxo de troca de transações financeiras para o ambiente externo. Atualmente, quanto mais desenvolvida é uma sociedade, mais desenvolvido e mais dinâmico é o seu mercado de capitais.

Por ser um canal essencial para a obtenção de recursos que permite o desenvolvimento de empresas e entidades governamentais, movimentando a economia através da geração de empregos e renda, por exemplo, o mercado de ações e títulos se apresenta como uma importante opção de investimento para pessoas e organizações. De acordo com a publicação da BOVESPA (2010):

Todo investidor busca a otimização de três aspectos básicos em um investimento: retorno,
prazo e proteção. Ao avaliá-lo, portanto, deve estimar sua rentabilidade, liquidez e grau de
risco. A rentabilidade é sempre diretamente relacionada ao risco. Ao investidor cabe definir
o nível de risco que está disposto a correr, em função de obter uma maior ou menor
lucratividade.

À medida que o nível de vida de uma sociedade cresce é possível observar que um dos critérios para avaliação deste crescimento é o aumento da renda per capita. Considerando este aumento, o mercado de capitais passa a ter uma parcela maior de investimentos, haja vista que aumenta a parcela de capital investido pela população. Vale ressaltar que para esta afirmação devemos considerar os fatores de influência macroeconômica, tais como as políticas fiscal, cambial e monetária, que afetam o consumo e o investimento.

Ainda de acordo com a mesma fonte "a poupança individual e a poupança das empresas (lucros) constituem a fonte principal do financiamento dos investimentos de um país". Tais aplicações e investimentos são os fatores motivadores do crescimento econômico. Este é o processo de circulação de capital, presente no desenvolvimento econômico. As organizações, à medida que crescem e se desenvolvem, precisam de mais recursos que podem ser obtidos por meios diversos tais como empréstimos de terceiros (que, na maioria das vezes, são provenientes de instituições financeiras), reinvestimento dos lucros auferidos e a participação de acionistas. É por meio da participação dos acionistas que uma organização ganha condições de obter novos recursos para aumentar e/ou aprimorar suas atividades operacionais em contrapartida à participação no seu capital.

Mas a decisão de investir em uma determinada empresa, frequentemente vem sendo considerada uma aposta de alto risco. Determinar, por exemplo, quais são as ações que devem compor a carteira de um investidor envolve um conhecimento amplo acerca da gestão das empresas 
para saber o seu potencial de geração de lucro. Essas informações afetam diretamente o valor da ação e podem, caso haja alguma oscilação no mercado, determinar o lucro ou prejuízo da operação.

Os estudos sobre o assunto apontam no sentido de ser preciso compreender não somente o desempenho operacional da empresa, mas também o comportamento do próprio mercado como um todo. Nesse sentido, os decisores precisam analisar aspectos tais como: as informações sobre a posição de outros investidores, ou se os mesmos pretendem aumentar ou diminuir suas carteiras; a situação atual do ambiente político nacional; os rumos que o Ministério do Planejamento e o Banco Central apontam para economia, entre outras informações. Como essas informações muitas vezes não são compreendidas de forma integrada por um investidor, é preciso desenvolver ferramentas capazes de entender e solucionar as demandas desses investidores.

Não obstante, os métodos de apoio à decisão têm colaborado sobremaneira na tarefa de criar um sistema racional de escolhas, bem como realizar um mapeamento dos padrões de decisão, porém, não se pode propor ferramentas e soluções para processos que não são totalmente entendidos. Nesse sentido, chegam-se assim, às seguintes questões: quais os fatores mais relevantes que diferentes agentes do mercado de ações levam em conta em seus momentos de escolha? Seria possível utilizar um método de apoio à decisão para identificar subjetividades na tomada de decisão dos agentes de mercado de ações?

Com base neste contexto, o objetivo principal do presente trabalho é provocar a reflexão acerca da necessidade de se mapear o perfil dos investidores do mercado de ações brasileiro utilizando o Método da Análise Hierárquica para identificar os motivos que mais influenciam na hora de comprar e vender uma ação. A partir dos resultados obtidos em nossa pesquisa de campo, correlacionamos tais resultados com a ciência das finanças comportamentais, com o objetivo de justificar e embasar as conclusões obtidas a partir deste trabalho.

\section{Mercado de ações}

A BOVESPA (2010) define o Mercado de Capitais como um sistema de distribuição de valores mobiliários, que tem o objetivo de proporcionar liquidez aos títulos de emissão de organizações e viabilizar a sua capitalização. Tal conceito é viabilizado pelas bolsas de valores, sociedades corretoras e outras instituições financeiras autorizadas. No mercado de capitais os principais "produtos" comercializados são as mini-fatias das organizações listadas nas bolsas de valores. A estas mini-fatias que são comercializadas com o objetivo de financiar as organizações, fornecendo ao investidor uma parte do seu capital social em troca do valor agregado por esta parte do capital pago pelo comprador. O investidor é remunerado em função da performance das operações do negócio da organização e operações não rotineiras, através de dividendos. A estas fatias da organização o mercado financeiro denomina “Ações". Destarte, existem muitos outros 
produtos que são transacionados no mercado de capitais tais como os empréstimos tomados pelas organizações, via mercado, que são, por exemplo, as debêntures conversíveis em ações, os bônus de subscrições e outros instrumentos que permitem a circulação do capital para financiar o desenvolvimento econômico da sociedade.

O mercado de capitais atinge ainda, as negociações com direitos e recibos de subscrição de valores mobiliários, certificados de depósitos, ações e demais derivativos em negociação.

Além da caracterização citada sobre as operações envolvidas no Mercado de Capitais, Ross et al (2008) caracterizam o funcionamento do Mercado de Capitais em dois segmentos; mercados primários e mercados secundários para os títulos de dívida e ações. O mercado primário está relacionado à venda original dos títulos pelas organizações ao mercado. O fator gerador de uma negociação de títulos de uma organização através do mercado primário foi caracterizado na seção acima. Já o mercado secundário envolve as transações nos quais os títulos, já emitidos e negociados em bolsa de valores para o caso de "Ações". O objetivo deste artigo está direcionado a analisar o mercado secundário.

Há dois tipos de mercados secundários: o mercado de leilões e o mercado de corretagem. Em geral, as corretoras compram e vendem para suas próprias carteiras, ou seja, operam para si mesmas, por seu próprio risco. Um vendedor de carros, por exemplo, compra e vende automóveis. Por outro lado, os operadores e os agentes conectam ou agrupam os compradores e os vendedores, mas eles não têm realmente a mercadoria que é comprada ou vendida. Um agente imobiliários, por exemplo, realmente não compra nem vende casas.

Os mercados de corretagem de ações e de títulos de dívida de longo prazo são chamados de mercados de balcão (Over the Counter - OTC). A maioria das negociações de títulos de dívida ocorre no balcão. A expressão mercado de balcão refere-se ao tempo em que os títulos eram literalmente comprados e vendidos em balcões de escritório em todo o país. Hoje, uma fração significativa do mercado de ações e quase todo o mercado de dívida de longo prazo não têm localização central: as várias corretoras estão conectadas eletronicamente.

Os mercados de leilões diferem dos mercados de corretagem de duas maneiras. Em primeiro lugar, em um mercado de leilões, ou câmbio, tem uma localização física (como Wall Street). Em segundo lugar, em um mercado de corretagem, a maioria da compra e venda é realizada pela corretora. A principal finalidade do mercado de leilões, por outro lado, é reunir aqueles que querem vender com aqueles que desejam comprar. As corretoras tem um papel limitado.

Como podemos observar, de acordo com os conceitos acima, os mercados secundários impactam e tem papel fudamental no mercado de capitais, na economia e no desenvolvimento de um países. Uma participação fundamental neste setor, como integrantes deste, são os investidores pessoa física o qual submetos como fator de análise neste artigo científico. 


\subsection{As razões que levam a investir no mercado de capitais}

À medida que o nível de vida de uma sociedade cresce é fato observar que um dos critérios para avaliação deste crescimento é o aumento da renda per capita. Considerando este aumento, o mercado de capitais passa a ter uma parcela maior de investimentos, considerando que aumenta a parcela de capital disponível dos investidores realizarem aplicações financeiras. Vale ressaltar que, para emitir esta afirmação devemos considerar os fatores de influência macroeconômica, tais como as políticas econômicas que afetam o consumo e o investimento. De acordo com a Bovespa (2010) "A poupança individual e a poupança das empresas (lucros) constituem a fonte principal do financiamento dos investimentos de um país".

É a partir da participação dos acionistas que uma organização aufere condições para obter novos recursos com vistas a aumentar e/ou aprimorar suas atividades operacionais em contrapartida à participação no seu capital.

Os analistas do mercado de ações se dividem basicamente em dois grupos, que são os analistas fundamentalistas e os analistas técnicos. A denominação destes grupos está diretamente ligada ao método que auxilia na tomada de decisão do investidor.

A Análise Fundamentalista está voltada para os fundamentos das empresas, expressos por meio das suas demonstrações financeiras. De acordo com Piazza (2008) a análise fundamentalista sugere que os papéis sejam analisados por meio dos fundamentos da empresa, ou seja, fundamentos expressos através de indicadores de análise, tais como a relação preço/lucro, o grau de endividamento, o patrimônio líquido, o pagamento de dividendos, entre outros. Tais indicadores são capazes de permitir a elaboração de um diagnóstico acerca da situação financeira das empresas. Eles expressam o andamento da atividade operacional e seu impacto nos lucros, permitindo uma avaliação da performance da companhia. Notícias sobre fusões e aquisições ou venda da organização também costuma afetar fortemente a percepção dos investidores fundamentalistas. Com base nessas análises, caso os indicadores evidenciem condições favoráveis, então as ações tendem a se valorizar. Analogamente, eles podem apontar indícios de queda nos preços dos ativos negociados. De forma geral, a análise fundamentalista tem uma orientação maior para a avaliação dos fundamentos da empresa.

Os analistas costumam dividir a análise fundamentalista em: a análise financeira e análise fundamentalista. A análise financeira baseia-se, sobretudo, na análise dos demonstrativos financeiros da empresa para determinar a sua posição financeira atual, assim como desempenho futuro. A análise fundamentalista determina o preço justo das ações da empresa, baseando-se em uma série de instrumentos, tais como: indicadores de liquidez, de rentabilidade, de giro, de alavancagem, e nos múltiplos de mercado de ações de empresas similares. 
Por sua vez, a análise técnica, de acordo com Bodie et al (2010), tanto se ocupa dos gráficos de históricos de cotações (e, por isso, é denominada de grafismo), quanto de aspectos tais como os volumes de transações e quaisquer padrões de comportamento de preços. A análise técnica tenta explorar padrões recorrentes e previsíveis no preço das ações para gerar um melhor desempenho de investimento. Os técnicos não negam o valor da informação fundamental, mas crêem que os preços não respondem imediatamente, dando margem à possibilidade de ganhos. Os analistas técnicos consideram que mudanças nos fundamentos do mercado podem ser discernidas antes de o impacto dessas mudanças ser refletido nos preços. Enquanto o mercado se ajusta, os técnicos exploram estas tendências.

Os analístas técnicos se baseiam na Teoria Dow, cujo nome homenageia o seu criador, Charles Dow. Ela já é considerada ultrapassada, e procura identificar tendências de longo prazo nos preços do mercado acionário. A Teoria Dow postula que existem 3 forças que afetam o preço das ações simultaneamente: a tendência primária; as tendências secundárias; e as tendências terciárias. Esta teoria incorpora noções de níveis de apoio e resistência nos preços das ações, que são determinados pela história recente dos preços. Um nível de apoio é o valor abaixo do qual é relativamente improvável o mercado cair. Por sua vez, o nível de resistência é o nível acima do qual é relativamente improvável o mercado subir. Quando é rompido um nível de apoio ou de resistência, é um sinal de que houve uma ruptura estrutural no padrão, de tal forma que os preços deverão aprofundar o comportamento da trajetória. Ou seja, se foi ultrapassado o nível de resistência é um sinal de que os preços deverão subir ainda mais, ou seja, é um sinal de compra. Por outro lado, se foi ultrapassado o nível de apoio é um sinal de que os preços deverão cair ainda mais, ou seja, é um sinal de venda. Os analistas técnicos usam alguns indicadores além dos gráficos para avaliar perspectivas de quedas ou avanços no mercado. Existem 3 tipos: indicadores de sentimento; indicadores de fluxos de fundos; e indicadores de estrutura de mercado.

Em outras palavras a análise técnica basea-se no estudo do comportamento do mercado, principalmente através de gráficos. A análise técnica proporciona ao investidor a possibilidade de identificar tendências de mercado e oferece um modelo de decisão para aqueles que operam no mercado, principalmente no curto prazo.

Piazza (2008) argumenta que a Análise Técnica se interessa pela análise gráfica do papel e de seu desempenho ao longo do tempo. Os premissas básicas para a análise são a cotação atual dos papéis, o preço máximo, médio, mínimo, o volume do dia, o fechamento anterior, o IFR (Índice de Força Relativa), as tendências, entre outros. O objetivo é identificar linhas de tendências e pontos de reversão do mercado por meio dos gráficos gerados com essas informações.

Em suma, a análise Técnica baseia-se no princípio de que os preços de ações se movem em tendências persistentes ao longo do tempo. Ou seja, os preços e volumes históricos de uma ação 
influenciam as flutuações futuras, de forma que uma vez determinada a tendência, é possível saber qual o melhor momento para comprar ou vender uma ação.

\section{Finanças comportamentais}

As Finanças Comportamentais procuram explicar os efeitos do comportamento humano sobre as decisões dos agentes econômicos, confrontando estas decisões com os pilares que sustentaram a Teoria Econômica, tais como a racionalidade e a otimização como meta fundamental da tomada de decisão.

Mesmo considerando os múltiplos conceitos e técnicas que auxiliam a tomada de decisão do investidor de renda variável, das quais apenas uma parte mínima está contemplada neste artigo, alguns estudos mostram que uma série de fatores psicológicos influenciam na tomada de decisão, principalmente do pequeno investidor que está menos preparado para suportar a pressão e a dinâmica complexa que o mercado de capitais impõe sobre os agentes participantes.

As Finanças Comportamentais estudam os supostos erros que os investidores cometem nas decisões econômicas (uma vez que violam os seus pressupostos de racionalidade), e possibilitam uma maior compreensão acerca das tendências do comportamento humano, que podem ajudar ou prejudicar os investimentos. Este recente campo de estudo dos Mercados Financeiros analisam sob outras abordagens a questão do processo de decisão e questiona o antigo pressuposto de que os investidores agem sempre racionalmente nas decisões financeiras.

De acordo com Macedo Jr et al (2011), a ajuda da psicologia, aliada aos avanços da tecnologia, que permite observar o cérebro em funcionamento, permitiu a verificação da existência de dois processos que afetavam as decisões econômicas. Um deles consiste nos processos automáticos de decisão, que são chamados de atalhos mentais, e que muitas vezes fazem com que o investidor cometa erros sérios no processo de tomada de decisão. $\mathrm{O}$ outro consiste nos processos de interferências, que acontecem com freqüência, do sistema afetivo nas nossas decisões do dia-a-dia, pricipalmente no mercado de capitais, onde, em uma fração de segundo, todo um contexto pode ser alterado e quantias significativas de dinheiro podem estar envolvidas.

A origem do conceito das Finanças Comportamentais, de acordo com Rogers et al (2007), verificou-se em função das restrições aparentes dos modelos financeiros atuais em explicar alguns eventos econômicos. As Finanças Comportamentais assumem dois presupostos fundamentais enunciados a seguir:

a) É a racionalidade limitada dos agentes econômicos, diferentemente da racionalidade ilimitada preconizada pela teoria neoclássica, que contribui sobremaneira para a formação de preços. 
b) Os limites à arbitragem devido a várias decisões erradas dos agentes não necessariamente criam oportunidades de arbitragem sem risco para outros agentes.

Nas teorias de finanças comportamentais, autores tais como Simon (1976), Kahneman e Tversky (1979) argumentam que, no ambito real, as decisões perfeitas podem se tornar custosas e a tendência alternativa a estes custos são as soluções "satisfatórias" para a tomada de decisões.

Dentre as formulações teóricas relativas às Finanças Comportamentais destaca-se a teoria do prospecto, que busca explicar os vieses cognitivos (heurísticos) no processo de tomada de decisão. Conforme ensinam Rogers et al (2007), esta teoria sugere que o processo de tomada de decisão não é estritamente racional, particularmente quando o tempo disponível é limitado, ao invés disto, os tomadores de decisão usam atalhos mentais no processo.

Os autores apresentam três exemplos típicos de ilusões resultantes do uso de processos cognitivos enviesados:

- Efeito certeza: as pessoas tendem a dar maior peso às possibilidades que têm alta probabilidade de acontecer;

- Efeito reflexão / aversão à perda: os agentes tendem a ser avessos ao risco quando estão diante de duas possibilidades de ganho com a mesma utilidade esperada e tendem a ser tomadores de risco quando as mesmas possibilidades apresentam no domínio das perdas;

- Efeito isolamento: para simplificar o processo de decisão os agentes geralmente desconsideram boa parte das características de cada uma das opções de escolha e centralizam sua análise sobre os componentes que distinguem as opções de escolha.

Dessa forma, ao contrário do que seria esperado na lógica da racionalidade neoclássica, a teoria das finanças comportamentais coletou evidências de que os investidores são propensos a riscos no domínio das perdas e avessos a risco no domínio dos ganhos, ou seja, esse conceito revela que os investidores são avessos à perdas e não ao risco. Mesmo que estas perdas possam não aparecer momentaneamente em determinada ação e que porventura no longo prazo possam parecer qualitativamente inadequados.

Adicionalmente à ênfase no aspecto de aversão à perda os teóricos das Finanças Comportamentais trabalham o conceito de aversão ao arrependimento. Com base nos autores citados observamos a constatação que é muito doloroso para os investidores assumirem seus erros, fazendo com que eles tenham um comportamento não maximizador da utilidade esperada somente para evitar reportar uma perda. O medo do arrependimento faz com que pessoas tomem decisões de forma irracional, criando molduras cognitivas que as deixam cegas aos dados históricos e principalmente às probabilidades estatísticas.

Tanto o efeito certeza quanto o efeito isolamento parecem estar relacionados diretamente ao conceito da utilização de regras de bolso, uma vez que os indivíduos tendem a analisar apenas parte 
do problema e dar maior importância a eventos com probabilidades maiores independente do fato de terem retornos esperados menores. Ademais, algumas regras de bolso podem estar viesadas, o que torna a escolha das regras voltada para alguma direção e promove a possibilidade de erros sistemáticos.

Kahnemsn \& Tversky (1979) ressaltam que os indivíduos violam sistematicamente algumas regras da teoria de probabilidade. Os agentes dão peso exagerado a informações extraídas de pequena base de dados - pessoas tendem a acreditar na "Lei dos Pequenos Números".

Estudos empíricos e experimentais realizados por equipes de diversas áreas (como psicólogos e economistas) têm mostrado que existem inumeras situações em que o comportamento dos agentes nos mercados financeiros se desvia bastante da racionalidade suposta pela teoria neoclássica. Dois exemplos podem ser apontados:

1. Investidores dão valor exagerado às noticias favoráveis sobre empresas cujas ações tiveram um desempenho bom em passado recente e ignoram boas informações sobre as de desempenho ruim (De Bondt e Thaler, 1985). Tal situação é um exemplo claro de imperfeição e viés na coleta e armazenagem das informações pelos investidores. Tal situação é um exemplo claro de imperfeição e viés na coleta e armazenagem das informações pelos investidores.

2. Investidores nos mercados financeiros tendem a não aceitar perdas (loss avertion) relutando a se desfazer de posições em que tenham prejuízo enquanto liquidam rapidamente posições vencedoras (De Bondt e Thaler, 1985). O contexto em que o problema é apresentado e fatores psicológicos afetam a tomada de decisão.

\section{O grau de adequação e a cientificidade do método da análise hierárquica para a ordenação das preferências}

Com base nas questões doutrinárias acerca das metodologias multicritério de tomada de decisão formamos convencimento no sentido de que seja possível, de alguma forma, a agregação das preferências individuais, em escala cardinal, baseadas em comparações interpessoais.

A questão principal então é encontrar uma metodologia que permita, de forma eficiente, esboçar uma representação da função de bem estar agregada, para um dado conjunto de indivíduos de maneira a subsidiar a tomada de decisão na escolha da ferramenta de análise que melhor auxilie os investidores sobre qual ação investir.

O Método da Análise Hierárquica - MAH, que foi desenvolvido por Saaty em 1972, oferece algumas vantagens operacionais para realização de uma ordenação, sobretudo em razão de sua consistência lógica. De um modo geral, quando os investidores necessitam escolher diferentes carteiras de ações eles podem depender de julgamentos e de juízos de valor, que nem sempre evidenciam escolhas racionais ou consistentes conforme citado na seção anterior deste artigo. 
As tomadas de decisão referem-se muitas vezes às entidades cuja definição é, de certa forma, vaga. A vaguidade das definições impede uma modelagem das variáveis envolvidas que permita sua validação empírica, e conseqüente confirmação. Sem a validação empírica e a confirmação, não há como atribuir foro de cientificidade à teoria modelada. É requerida então uma metodologia que permita algum tipo de confirmação e validação para o modelo teórico estabelecido.

O MAH tem como característica principal a estruturação das entidades envolvidas no contexto de que se está tratando, sob a forma de uma hierarquia, onde o nível mais elevado será representado por uma função objetivo, ou meta desejável a ser atingida, ou ainda, como um atributo desejável a ser verificado. Esta meta desejável, por sua vez, será resultado da presença de critérios ou pressupostos condicionantes, que interagem de forma a contribuir para este objetivo desejado. Não obstante, neste momento é importante saber em que grau ou intensidade cada critério de decisão contribui para a meta alvo, de maneira que se tenha uma visão relativa da importância desse critério para o resultado final. Tal como numa distribuição de Pareto, onde existem "poucos, mas muito importantes", e "muitos, mas pouco importantes".

Entrementes, quando esta questão é apresentada, em razão da absoluta ausência de uma relação determinística que nos permita inferir acerca do modelo, resta-nos apenas a subjetividade para formulação de juízos de valor. Este é o problema clássico com que a análise econômica se depara quando busca medir o bem-estar dos indivíduos quando são submetidos à variações de preços e rendas no mercado. Como seria possível medir a satisfação ou o bem-estar dos agentes econômicos? A solução apresentada pela doutrina econômica foi considerar que os agentes econômicos possuem uma ordem de preferências, e que esta mantém certa lógica ordinal e cardinal. No MAH, busca-se encontrar as relações cardinais e ordinais entre os critérios que determinam a meta alvo. Analogamente à análise econômica, espera-se que os resultados obtidos possuam consistência lógica, ou seja, mantenham a racionalidade. A garantia da racionalidade deverá ser obtida com a confirmação do modelo, a partir de sua validação empírica. Na medida em que esta validação é verificável, através de um adequado tratamento matemático, fica garantida a cientificidade do método.

Desdobrando-se o raciocínio, a estrutura hierárquica vai se expandindo conforme a complexidade da meta alvo e de seus critérios. Os critérios podem dar origem a vários subcritérios, em outros níveis da hierarquia, e estes também podem ser expandidos, se for o caso. Fechando a estrutura entram as alternativas de escolha que se pretende comparar. Estas alternativas devem se relacionar completa e diretamente com o último nível hierárquico do construto modelado, em nível de subcritério certamente. Para cada subcritério considerado, as alternativas listadas devem ser submetidas a uma comparação com as demais, onde os "pesos" relativos de cada uma delas deverão 
ser declarados por "experts", baseados em juízos de valor, e submetidas à verificação de consistência lógica. Esta etapa é denominada relacionamento paritário de alternativas. No relacionamento paritário de alternativas, a subjetividade das preferências e juízos de valor são transformados em dados quantitativos, ou "pesos", assumindo os valores:

Tabela 1: Escala de Saaty

\begin{tabular}{|c|c|}
\hline Escala verbal & Escala numeral \\
\hline Alternativa A é igual a B & 1 \\
\hline Alternativa A é fracamente melhor que a B & 3 \\
\hline Alternativa A é moderadamente melhor que a B & 5 \\
\hline Alternativa A é fortemente melhor que a B & 7 \\
\hline Alternativa A é absolutamente melhor que a B & 9 \\
\hline
\end{tabular}

O autovetor principal de cada matriz de relacionamento paritário representará, para cada uma das alternativas, um resultado de posicionamento ordinal e cardinal em face do objetivo pretendido ou, com mais rigor, em relação à função objetivo pré-definida. A validação empírica dos resultados obtidos, tidos como sendo a expressão fática da racionalidade dos "experts", será verificada a partir da análise da consistência das escolhas feitas no relacionamento paritário. A consistência da relação será obtida a partir do autovalor principal da matriz recíproca gerada. Este autovalor determinará um certo índice de consistência. A relação entre este índice de consistência e certo índice randômico obtido a partir da geração de matrizes simétricas, deverá ser um resultado próximo de 0,1 . Se este resultado for obtido, a relação será dita consistente e a validação empírica do modelo estará assegurada.

O Método de Análise Hierárquica permite o estabelecimento deste "consenso" transitivo e consistente, bem como, nos oferece uma base cardinal de comparação entre alternativa. Por fim, destaca-se que como o resultado do método da análise hierárquica é uma alocação ordinal e cardinal de preferências.

\section{Aplicação do método com diferentes tipos de investidores: um ensaio no uso do método da análise hierárquica para a obtenção de preferências}

O estudo que motivou a presente pesquisa, envolvendo sua aplicação junto aos investidores do mercado de ações, justifica-se pelo fato de que informações colhidas no site da BMF BOVESPA mostram que a bolsa brasileira tem um volume financeiro médio mensal de 120 bilhões de reais durante o ano de 2011.

Neste trabalho de campo, procuramos reproduzir uma estrutura hierárquica onde a meta alvo consiste em identificar os perfis dos diversos públicos que investem no mercado e apurar o grau de coerência interna, sob a ótica da racionalidade, na tomada de decisão desses investidores de diferentes níveis. Tais critérios, e os seus pressupostos condicionantes, seriam as próprias 
alternativas de escolha, que convergiriam para a meta alvo. Estas alternativas de escolha representam as variáveis da função de bem estar agregada, que foi anteriormente definida.

O objetivo do trabalho consistiu em verificar se uma ferramenta de apoio à decisão é capaz de ajudar no mapeamento do perfil do investidor brasileiro e, não necessariamente, definir esse perfil. Dessa forma, foram aplicados questionários a diferentes agentes que investem no mercado de ações. Nestes questionários pedia-se que o entrevistado fizesse uma comparação par-a-par dos fatores de tomada de decisão de acordo com suas preferências, em termos de 4 critérios teste. Para os julgamentos oferecemos a escala de Saaty, apresentada no quadro 1.

Para o experimento, foi estruturada a seguinte hierarquia, com os respectivos relacionamentos paritários:

Figura 1 - Hierarquia do estudo de caso

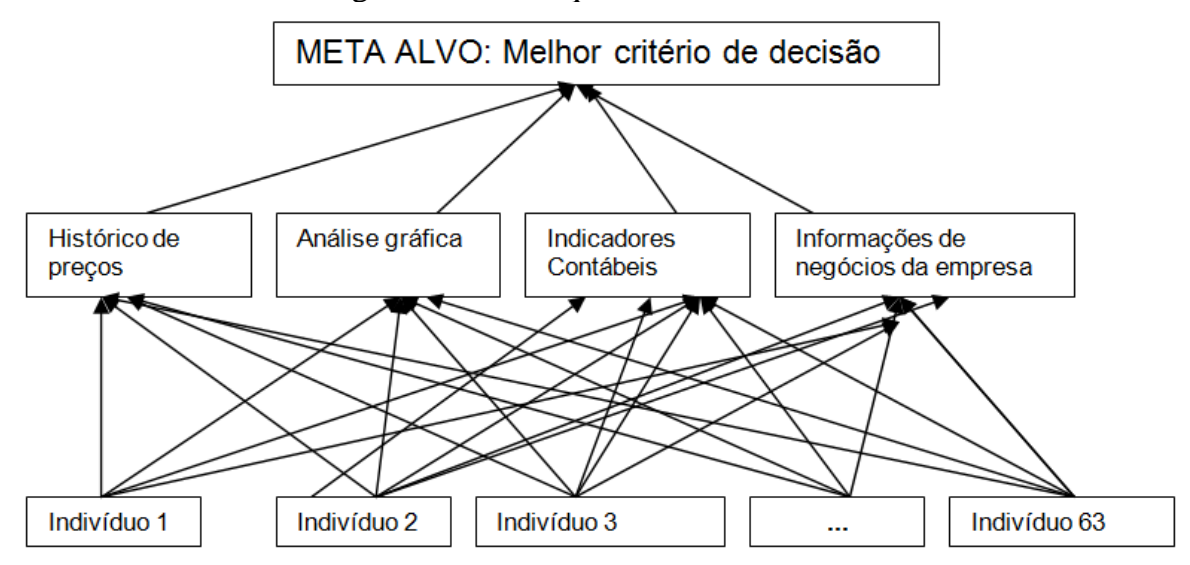

Fonte: Desenvolvimento próprio

O grupo de investidores pesquisados foi estratificado em três categorias (perfis de investidores) detalhadas a seguir:

1) Investidor leigo: nesta classificação enquadram-se pessoas que tem uma vaga noção do funcionamento do mercado de ações, no entanto, nunca investiu nenhuma quantia de seu capital no mercado.

2) Investidor intermediário: nesta classificação enquadram-se pessoas que investem regularmente uma parte de seu capital no mercado de ações, no entanto, fazem desta atividade uma forma de adquirir receita não operacional, ou seja, estes investidores atuam em diferentes setores de atividade, mas não diretamente no mercado financeiro. Eles operam mais especificamente comprando e vendendo ações.

3) Investidor de mercado: nesta classificação enquadram-se os profissionais do mercado financeiro, que atuam especificamente nesses mercados.

No decorrer do experimento verificou-se alguma dificuldade em se determinar o número de investidores leigos e intermediários. Dessa forma, foram aplicados 63 questionários a pessoas que se enquadravam em cada uma das descrições anteriores - o critério de pessoas escolhidas envolveu 
a acessibilidade dos pesquisadores com esse público. Essa decisão exige um exercício em relativizar o resultado obtido, porém, como o objetivo da pesquisa não foi determinar o perfil do investidor e sim verificar se a ferramenta é capaz de colaborar com a análise, o procedimento foi então aceito.

Com objetivo de facilitar o entendimento do processamento do Método da Análise Hierárquica, apresentamos a seguir o formulário e o processo feito para 1 indivíduo da pesquisa, ao julgar as opções. Este procedimento determinou então a construção de uma matriz recíproca, que refletisse o relacionamento paritário entre as alternativas. Foi calculado o autovalor da matriz representativa da escolha. Em seguida, o autovalor gerou o índice de consistência correspondente de sua matriz recíproca. Este índice de consistência foi comparado com os índices randômicos de matrizes recíprocas de ordem quatro, para a determinação das razões de consistência.

No formulário, o entrevistado deveria ter como foco a seguinte questão: compare e assinale o grau de importância que cada um dos fatores a seguir representam, para você, no momento de comprar uma ação: Histórico do preço; Análise gráfica; Indicadores Contábeis; e Informações de negócios da empresa.

A figura a seguir apresenta a tabulação de um entrevistado:

\begin{tabular}{|c|c|c|c|c|c|c|c|c|c|c|}
\hline & \multicolumn{9}{|c|}{ Figura 2 - Exemplo de Julgamento } & \\
\hline & 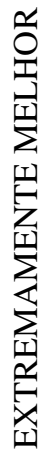 & 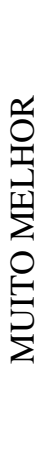 & 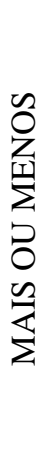 & 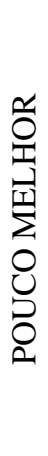 & 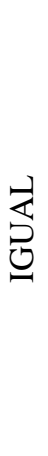 & 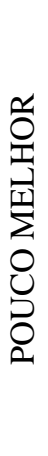 & 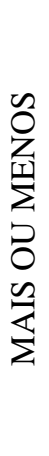 & 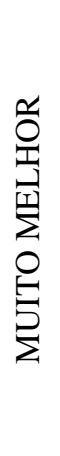 & 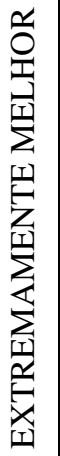 & \\
\hline Histórico do preço & 9 & 7 & $\mathbf{X}$ & 3 & 1 & 3 & 5 & 7 & 9 & Análise gráfica \\
\hline Histórico do preço & 9 & 7 & 5 & $\mathbf{X}$ & 1 & 3 & 5 & 7 & 9 & Indicadores Contábeis \\
\hline Histórico do preço & 9 & $\mathbf{X}$ & 5 & 3 & 1 & 3 & 5 & 7 & 9 & $\begin{array}{c}\text { Informações de negócios da } \\
\text { empresa }\end{array}$ \\
\hline Análise gráfica & 9 & 7 & 5 & 3 & 1 & $\mathbf{X}$ & 5 & 7 & 9 & Indicadores Contábeis \\
\hline Análise gráfica & 9 & 7 & 5 & $\mathbf{X}$ & 1 & 3 & 5 & 7 & 9 & $\begin{array}{c}\text { Informações de negócios da } \\
\text { empresa }\end{array}$ \\
\hline $\begin{array}{l}\text { Indicadores } \\
\text { Contábeis }\end{array}$ & 9 & 7 & 5 & 3 & 1 & 3 & $\mathbf{X}$ & 7 & 9 & $\begin{array}{c}\text { Informações de negócios da } \\
\text { empresa }\end{array}$ \\
\hline
\end{tabular}

Fonte: Desenvolvimento próprio

Esse julgamento transformou-se na seguinte matriz: 
Tabela 2: Exemplo de julgamento: matriz.

\begin{tabular}{|c|c|c|c|c|}
\hline & $\begin{array}{c}\text { Histórico do } \\
\text { preço }\end{array}$ & Análise gráfica & $\begin{array}{c}\text { Informações de } \\
\text { negócios da empresa }\end{array}$ & $\begin{array}{c}\text { Indicadores } \\
\text { Contábeis }\end{array}$ \\
\hline Histórico do preço & 1 & 5 & 3 & 7 \\
\hline Análise gráfica & $1 / 5$ & 1 & $1 / 3$ & 3 \\
\hline $\begin{array}{c}\text { Informações de } \\
\text { negócios da empresa }\end{array}$ & $1 / 3$ & 3 & 1 & 5 \\
\hline Indicadores Contábeis & $1 / 7$ & $1 / 3$ & $1 / 5$ & 1 \\
\hline
\end{tabular}

Fonte: Desenvolvimento próprio com base nos dados da pesquisa

O passo seguinte requer a normalização das colunas da matriz. Este procedimento consiste na soma dos componentes das colunas, e na posterior divisão de cada componente por esta soma. Passamos em seguida para a obtenção de um vetor resultante da média da soma das linhas. Este é o autovetor ou vetor das prioridades, que evidencia a escala de preferências ordinais e cardinais das alternativas, expresso conforme a tabela mostrada em seguida:

Tabela 3: Exemplo de julgamento: matriz

\begin{tabular}{|c|c|}
\hline Opção & Pontos \\
\hline Histórico do preço & 0,558 \\
\hline Análise gráfica & 0,122 \\
\hline Informações de negócios da empresa & 0,263 \\
\hline Indicadores Contábeis & 0,057 \\
\hline
\end{tabular}

Não obstante, precisamos verificar se estes resultados estão coerentes com o pressuposto de racionalidade, ou seja, devemos calcular o autovalor principal desta matriz e, em seguida, comparar o índice de consistência obtido com o índice randômico das matrizes recíprocas de ordem quatro, para obtenção de uma razão de consistência inferior a 0,1 . Devemos assim multiplicar a matriz original por este vetor, obtendo um novo vetor $4 \times 1$. O passo seguinte consiste em dividir os componentes deste vetor pelos componentes do autovetor de prioridades, obtendo-se o novo vetor. Extraindo-se a média dos componentes deste vetor obtemos o número 4,118, que é o autovalor máximo. Com o autovalor máximo desta matriz de relacionamentos, obtêm-se o índice de consistência, conforme a expressão seguinte:

$$
\text { I.C. }=(\lambda \max -n) /(n-1)=(4,118-4) / 3=0,039
$$

Dividindo-se este resultado pelo índice randômico para matrizes de ordem quatro, no valor de 0,90, encontramos um índice de consistência (IC) no valor de 0,044, o que é bastante aceitável, segundo o MAH, e vem apresentar uma evidência robusta com relação à racionalidade da escolha.

Com base nessa hierarquia individual, foram calculadas as médias e os respectivos desviospadrão acerca das preferências dos diferentes tipos de investidores. O resultado obtido na pesquisa foi: 
Tabela 4: Comparação de opiniões

\begin{tabular}{|l|c|c|c|c|c|c|}
\cline { 2 - 7 } \multicolumn{1}{c|}{} & \multicolumn{2}{c|}{ Leigos } & \multicolumn{2}{c|}{ Intermediários } & \multicolumn{2}{c|}{ Mercado } \\
\cline { 2 - 7 } \multicolumn{1}{c|}{} & MED & DP & MED & DP & MED & DP \\
\hline Histórico do preço & 29,77 & 12,33 & 19,43 & 13,04 & 12,37 & 9,46 \\
\hline Análise gráfica & 20,93 & 12,30 & 18,95 & 11,59 & 42,17 & 28,67 \\
\hline Indicadores Contábeis & 16,87 & 5,69 & 31,95 & 18,63 & 12,83 & 6,75 \\
\hline $\begin{array}{l}\text { Informações de negócios da } \\
\text { empresa }\end{array}$ & 32,40 & 14,84 & 29,65 & 23,89 & 32,03 & 25,84 \\
\hline \multicolumn{1}{|c|}{ Incoerência } & 49,70 & 59,18 & 14,30 & 13,88 & 9,53 & 8,45 \\
\hline
\end{tabular}

Fonte: Desenvolvimento próprio com base nos dados da pesquisa

\section{Análise dos resultados}

Em relação ao uso dos históricos de preços, os leigos apresentam, dentre os 3 grupos, o maior grau de uso dessa técnica. Isso pode ser resultado da quantidade de sites de orientação mercadológica, bem como os próprios portais mais conhecidos (globo, UOL, IG, etc) que abundam esse tipo de investidor com essas informações. Em outras palavras, essa é a informação mais disponível para esse tipo de investidor.

Em relação ao uso da análise gráfica, por ser um instrumento muito difundido nas escolas de economia e administração, a análise aparece como o instrumento mais importante para o investidor de mercado.

Em relação ao uso de indicadores contábeis destaca-se que este instrumento, por estar situado, do ponto de vista acadêmico, entre os dois anteriores, foi mais utilizado pelos investidores intermediários. Seriam aquelas pessoas que saem do senso comum para buscar informações disponíveis na internet e em bancos de investimento, mas que não são de interpretações simples para o leigo. Por outro lado, os investidores de mercado precisam de informações mais depuradas e tratadas para tomar suas decisões, pouco se utilizando dessa ferramenta. Não obstante, uma vez que dentre os investidores leigos existem muitos com formação na área financeira, também verificamos o uso da análise para supostamente reduzir a incerteza na escolha.

O destaque que o uso das informações de negócios da empresa ganhou na pesquisa surpreendeu os pesquisadores. Esperava-se que o maior uso fosse dentre os agentes de mercado, porém, os leigos também afirmavam utilizar-se dessa técnica. Isso pode indicar uma mudança no perfil do investidor brasileiro, uma tendência ou modismo, ou apenas uma informação que pode ser questionada pela limitação do método - que não buscou identificar necessariamente o perfil, mas apenas validar o uso da metodologia para o processo.

Em relação à incoerência, ou transitividade, verificamos que o comportamento esperado aconteceu, ou seja, os leigos apresentaram o maior grau de inconsistência. Provavelmente isto se verifica porque se trata de pessoas com perfis muito diferentes num mesmo grupo, dentre os 3 grupos analisados. Essa informação também é sugerida pelo alto desvio padrão apresentado. 


\section{Considerações finais}

Conforme citado anteriormente, este trabalho de campo procurou reproduzir uma estrutura hierárquica onde a meta alvo seria entender os perfis dos diversos públicos que investem no mercado e apurar o grau de coerência na tomada de decisão desses investidores de diferentes níveis. Para a sustentação do objetivo deste trabalho foram apresentadas as premissas e conceitos básicos envolvidos no mercado financeiro, mais especificamente no mercado de ações.

Os autores deste artigo buscaram ainda, mesmo antes da aplicação dos questionários supracitados, embasamentos teóricos acerca da racionalidade limitada inerente aos seres humanos e que por sua vez são fatores relevantes no processo de tomada de decisões no âmbito dos agentes do mercado financeiro. Os conceitos sobre Finanças Comportamentais foram significativos para análise dos resultados obtidos, uma vez que este ramo do conhecimento ciência nos antecipou a expectativa para o grau de incoerência observado em todas as classes de investidores analisados a partir da aplicação dos questionários.

Acerca do entendimento dos perfis dos agentes de mercado, o destaque com relação ao critério "uso das informações de negócios da empresa", surpreendeu os pesquisadores. Conforme citado anteriormente, esperava-se que o maior uso fosse dentre os agentes de mercado. Porém, vimos que os leigos também afirmavam utilizar-se dessa técnica. Isso pode indicar uma mudança no perfil do investidor brasileiro, ou apenas uma informação que pode ser questionada pela limitação do método.

Ainda com relação à incoerência observada, que é um fato que merece destaque a partir dos resultados neste trabalho, nos perfis "leigo, intermediário e investidor", fica evidenciado o propósito das finanças comportamentais acerca dos estudos dos erros que os investidores cometem nas decisões econômicas. Esta análise nos permitiu perceber alguns aspectos sobre a questão do processo de decisão, não confirmando o antigo pressuposto que os investidores agem sempre racionalmente nas decisões do ambiente do mercado financeiro.

Refletindo sobre os conceitos apresentados em Finanças Comportamentais, a partir dos resultados obtidos, verifica-se que, tanto o efeito certeza quanto o efeito isolamento parecem estar relacionados diretamente ao conceito da utilização de regras de bolso, uma vez que o grau de incoerência apresentado durante nossas análises tendeu a demonstrar que os indivíduos analisam apenas parte do problema e dão uma maior importância para a ocorrência de eventos isolados, com maiores probabilidades de ocorrência.

Algumas regras de bolso podem estar viesadas, o que torna a escolha das regras voltada para alguma direção e promove a possibilidade de erros sistemáticos, tais como as incoerências entre os fatores de análise usualmente utilizados mesmo para a classe de investidores com maior 
conhecimento. Neste sentido, cumpre observar que todas as classes de investidores analisadas neste trabalho, ou mais especificamente, os indivíduos contidos nesta e que participaram desta pesquisa, eventualmente violam algumas regras acerca da distribuição de probabilidade supostamente representativa do fenômeno descrito, ou seja, há um equívoco quanto ao modelo que representa o fenômeno.

\section{Abstract}

The decision to invest in a company through the capital market, often has been considered a highrisk bet. Determine, for example, what actions will comprise the portfolio of an investor involves broad knowledge of business management to learn their potential for generating profit. The main objective of this work is to induce discussions about the need to map the profile of investors in the Brazilian stock market using the Analytic Hierarchy Process, to identify the reasons that weigh more at the moment to buy and sell a stock. From the results obtained in our field research, we correlated these results with the science of behavioral finance in order to justify and support the conclusions obtained from this work. In this sense, questionnaires were administered to different people who invest in the stock market. In these questionnaires was asked the respondent to make a comparison pair-to-pair factors of decision-making according to their preferences in terms of four criteria test. This analysis allowed us to understand the issue of decision not confirming the old assumption that investors always act rationally in the decisions of the financial world.

Key-words: stock market; analytic hierarchy process; profiles of brazilian investors; behavioral finance.

\section{Referências}

ARROW, K. Social Choice and Individual Values. Second edition. John Wiley \& Sons. New Haven,1963.

BODIE, Z.; KANE, A.; MARCUS, A.J. Investimentos. Tradução Suely Sonoe Murai Cuccio. 8. ed. Porto Alegre: AMGH, 2010.

BOVESPA. Introdução ao Mercado de capitais. São Paulo: BM\&F Bovespa, 2010.

SIMON, H. From substantive to procedural rationality. In: Simon Models of Bounded Rationality. Boston: MIT Press, 1976.

DOWNING, D.; CLARK, J. Estatística aplicada. São Paulo: Editora Saraiva, 1998.

KAHNEMAN, D.; TVERSKY, A. Prospect theory: an analysis of decision under risk. Econometrica, p.263 - 291, March, 1979. crossref

MACEDO JR, J.S.; KOLINSKY, R.; MORAIS, J.C.J. de. Finanças Comportamentais: como o desejo, o poder, o dinheiro e as pessoas influenciam nossas decisões. São Paulo: Atlas, 2011.

MARCH, J.G. Racionalidade restrita, ambiguidade e a engenharia da escolha. Rio de Janeiro: Edições Multiplic, vol. $2, \mathrm{n}^{\circ} 5,1982$.

MAS-COLELL, A. Microeconomic Theory. Oxford University Press, New York, 1995.

NEUMANN, J. V.; MORGENSTERN, O. Theory of Games and Economic Behavior. Princeton: Princeton University Press, 1944.

PEARCE, D. W.; TURNER, R. K. Economics of natural resources and environment. Baltimore, Maryland: The John Hopkins University Press, 1990. 
PIAZZA, M.C. Bem-vindo a Bolsa de Valores. Ribeirão Preto: Ed. Novo Conceito, 2008.

ROGERS, P.; SECURATO, J. R.; RIBEIRO, K. C. S.; ARAUJO, S. R. Finanças Comportamentais no Brasil: Um Estudo Comparativo. In: $7^{\circ}$ Congresso USP de Controladoria e Contabilidade, São Paulo: 2007.

ROSS, S.; WESTERFIELD, R.; JAFFE, J. Administração financeira (Corporate Finance). 2.Ed. São Paulo: Ed. Atlas, 2008.

SAATY, T.L. Método de Análise Hierárquica. Tradução de Wainer da Silveira e Silva. São Paulo: Mc Graw - Hill, 1991.

VARIAN, H.R. Microeconomia: princípios básicos. Tradução da $4^{\mathrm{a}}$ edição americana por Ricardo Inojosa. Rio de Janeiro: Campus, 1999.

DE BONDT, W.; THALER, R. “Does the Stock Market Overreact?”. Journal of Finance, v. XI, n. 3, p. 793-808, 1985.

\section{Dados dos autores}

Nome completo: Eduardo Picanço Cruz D.Sc.

Filiação institucional: Universidade Federal Fluminense - UFF

Departamento: Empreendedorismo e Gestão

Função ou cargo ocupado: Prof Adjunto 4. Coordenador do Curso de Administração

Endereço completo para correspondência (bairro, cidade, estado, país e CEP): Rua Mário Santos

Braga 30/702 - Niterói - RJ - Brasil - CEP24220140

Telefones para contato: (21)26299868

e-mail: epicanco@vm.uff.br

Nome completo: Hugo Leonardo Costa Spindola

Filiação institucional: PricewaterhouseCoopers Auditores Independentes - PwC

Departamento: Advisory

Função ou cargo ocupado: Gerencial

Endereço completo para correspondência (bairro, cidade, estado, país e

CEP): Rua Alfredo Backer 989, 06/204, São Gonçalo - RJ, CEP: 24710-395

Telefones para contato: 21.973350440

e-mail: hugo.spindola@br.pwc.com

Nome completo: Carlos José Guimarães Cova D.Sc.

Filiação institucional: Universidade Federal Fluminense - UFF

Departamento: Contabilidade

Função ou cargo ocupado: Prof. Titular

Endereço completo para correspondência (bairro, cidade, estado, país e CEP): Rua Mário Santos 
Braga 30/711 - Niterói - RJ - Brasil - CEP24220140

Telefones para contato: (21)26299887

e-mail:cjcova@terra.com.br

Nome completo: Carlos Navarro Fontanillas M.Sc.

Filiação institucional: Universidade Federal Fluminense - UFF e Universidade Federal do Rio de Janeiro - UFRJ

Departamento: Administração de Macaé

Função ou cargo ocupado: Prof . Assistente (UFF) e Doutorando (COPPE/UFRJ)

Endereço completo para correspondência (bairro, cidade, estado, país e CEP): Rua Tonelero 380/603 Copacabana Rio de Janeiro CEP 22030-000

Telefones para contato: (21) 964121151

e-mail: navarro@pep.ufrj.br

Submetido em: 11/03/2013

Aceito em: 20/01/2014 